\title{
Acquiring the Cardinal Knowledge of Number Words: A Conceptual Replication
}

\author{
Laurence Rousselle $^{1 \S}$, Line Vossius ${ }^{1 \S}$ \\ [1] Research Unit for a life-Course perspective on Health \& Education (RUCHE), Faculty of Psychology, Speech Therapy and Education-University of Liège, Liège, \\ Belgium. \\ ${ }^{\S}$ These authors contributed equally to this work.
}

Journal of Numerical Cognition, 2021, Vol. 7(3), 411-434, https://doi.org/10.5964/jnc.7029

Received: 2020-07-30 • Accepted: 2021-06-22 • Published (VoR): 2021-11-30

Handling Editors: Mojtaba Soltanlou, University of Surrey, Guildford, UK; Krzysztof Cipora, Loughborough University, Loughborough, UK

Corresponding Author: Laurence Rousselle, University of Liège, Faculty of Psychology, Speech Therapy and Education, Place des Orateurs 1, Bât. B33 (Sart Tilman, Quartier Agora)- 4000 Liège- Belgium. E-mail: laurence.rousselle@uliege.be

Related: This article is part of the JNC Special Issue "Direct and Conceptual Replication in Numerical Cognition", Guest Editors: Mojtaba Soltanlou \& Krzysztof Cipora, Journal of Numerical Cognition, 7(3), https://doi.org/10.5964/jnc.v7i3

Supplementary Materials: Data [see Index of Supplementary Materials]

\begin{abstract}
Understanding the way in which counting represent numerosities was shown to be a long-lasting process. As shown in the Give-anumber task, acquiring the meanings of verbal number words goes through successive developmental stages in which children first learn the cardinal meanings of small number words one at a time before generalizing the cardinal principle they have induced from the first three number words to all number words within their counting range. This acquisition would take about a year, and would be completed by the age of $3 \frac{1}{2}$ years. The aim of the present study was to provide a conceptual replication of the developmental sequence described in Wynn's study nearly 30 years ago using the Give-a-number task. A first cross-sectional study was conducted on 213 Belgian children aged between 39 and 74 months using the Give-a-number task to examine the developmental pattern and the influence of age on this acquisition. The time span of acquisition was examined in a second study in which 34 children were tested five times every months between the age of 36 to 52 months. Results showed that acquiring the cardinal meanings of number words spread out over a protracted period, far more extended than assumed by Wynn. Furthermore, children do not generalize all-at-once to large number words, the cardinal knowledge they learned on small number words. Rather, number words were found to be learned one at a time in a really progressive manner. Results were discussed with regard to their implications for the existing theories and in relation with other tasks assessing the acquisition of verbal number symbols.
\end{abstract}

\section{Keywords}

numerical development, mathematics education, cardinality, cardinal principle, number words, number meaning, preschoolers, counting, Give-N, knower-levels

The last 50 years, many studies have been conducted to examine how young children come to understand the way counting represent numerosities in order to shed light on the nature of our early mathematical knowledge. One crucial part of this development regards the acquisition of the meanings of the number words. For a long time, the understanding of the cardinal meanings of number words was examined with the "How many?" task requiring children to tell how many objects were presented in a set. This task was supposed to examine children's knowledge of the cardinal principle, 
one of the five Gelman and Gallistel's (1978) counting principles which specifically involve understanding that the last number word uttered in counting represent the cardinal of the whole set. However, as children frequently experience the "How many?" question in everyday life, they have simply learned to repeat the last word uttered in counting to answer this question without a deep understanding of the cardinal value of number words.

Therefore, Wynn $(1990,1992)$ set up the "Give-a-number" task (GaN task), a new task in which children were asked to give a collection of objects corresponding to a verbal number word in order to determine whether children mastered the cardinal principle and, if not, which number words they knew consistently the cardinal meanings of. The goal was to examine the developmental sequence of number words cardinal meanings and to compare the consistency of performance across the "How many" and the GaN tasks. Surprisingly, results revealed a large discrepancy between performance in both tasks. Three-year-old children could count until numerosities larger than 4, numerosities that they could not even give or show on demand. Most children could provide a correct answer to the question "How many?" while they were completely unable to give a correct number of objects when asked for a specific numerosity within their counting range (Frye et al., 1989; Sarnecka et al., 2007; Sarnecka \& Carey, 2008). Therefore, the "How many" task was no longer considered to be a sufficient indicator of children's understanding of the cardinal meanings of number words and the GaN task was adopted as a much more reliable measure of children's level of cardinal knowledge.

Wynn (1992) used this task to track the acquisition of the cardinal meanings of number words in twenty American children who were followed longitudinally for a period up to 7 months and tested every 5 to 8 weeks. An in-depth analysis of children's pattern of development showed that, by the age of $3 \frac{1}{2}$ years, most of them mastered the cardinal meanings of all the number words within their counting range but this acquisition went through several developmental stages which laid the foundation of the knower-level theory. Children learned the cardinal meanings of small number words sequentially, one at a time, and in the order before being able to apply the cardinal principle to larger number words (within their counting range). In her sample, Wynn found one-knowers (i.e., children starting out with a cardinal knowledge limited to the number one with no knowledge of the meanings of two or larger number words) who progressively became two-knowers (i.e., children who master only the cardinal meanings of one and two but not of three and larger numbers) and then, three-knowers (i.e., children who know the cardinal meanings of number words up to three but no more). At this point, Wynn (1992) observed that all children who succeeded at giving the verbal number four, also succeeded at giving five. Seemingly, children figure out the cardinal principal of counting and come to generalise by induction the cardinal principle they have learned from the first three number words to all number words within their counting range (Sarnecka, 2021). They were called Cardinal-principle knowers (CP-knowers).

Moreover, the GaN task provided an interesting field of observations to identify the strategies used by children to solve the task. Wynn (1990) distinguished counters, that is, children who used counting to build a collection of objects, from grabbers who used another strategy consisting generally in grabbing and giving a handful all at once, irrespective of the requested numerosity. She found a relationship between the access to higher level of cardinal knowledge and the strategy used to solve the task. CP-knowers were found to be more likely to grab the correct number for small numbers and to count when asked for large number words while subset-knowers (SS-knowers) mainly used non-counting based strategies regardless of size of the requested numbers and remained at a lower level of cardinal knowledge (Wynn, 1990, 1992; see also Le Corre et al., 2006).

The seminal work of Wynn $(1990,1992)$ laid the groundwork for numerous researches interested in the development of basic numerical knowledge. According to Scopus (2021, May 16), the two core papers describing the acquisition of number word meanings have been cited no less than 538 and 471 times respectively, up to now. The pattern of acquisition underpinning the knower-level theory, specifically, the incremental stage of acquisition of small number words cardinal meanings followed by a generalisation of the cardinal principle to all known number words, has been replicated many times (Le Corre et al., 2006; Le Corre \& Carey, 2007; Negen \& Sarnecka, 2012; Sarnecka \& Carey, 2008; Sarnecka \& Gelman, 2004; Sarnecka \& Lee, 2009; Slusser et al., 2013; Slusser \& Sarnecka, 2011), even in secluded low numerated cultures (Piantadosi et al., 2014). In these studies, the knower-lever theory has been widely used to assess and classify children on the basis of their cardinal knowledge development before examining other numerical skills (see also Carey et al., 2017; Cheung et al., 2016; Le Corre, 2014; Wagner \& Johnson, 2011). Performance in the GaN was found to be subject to a large variability depending on different factors: the grammatical mark of the singular/dual/plural distinction in language (Almoammer et al., 2013; Sarnecka et al., 2007), the socioeconomic status (Sarnecka, Negen, \& 
Goldman, 2018; Scheuer et al., 2019) or the cultures (children from US, Japan and Russia, Sarnecka et al., 2007; or from the Tsimane, an indigenous farming-foraging group in Bolivia, Piantadosi et al., 2014).

Some attempts have been made to uncover the mechanisms underlying the particular pattern of learning at the basis of the knower-level theory. Actually, three quantification processes could compete to determine the quantity corresponding to symbolic numbers: subitizing, counting and estimating. Each of them relies on different mechanisms or procedure with heterogeneous level of maturity in children (see Piazza, 2011 for a review). Subitizing would exploit the Object Tracking System (OTS; Trick \& Pylyshyn, 1994), ${ }^{1}$ which is rather precise in nature and allow the child to keep track simultaneously of 3 or 4 objects in the visual field using a limited number of visuo-spatial tags. This mechanism, which would be functional very early in the development, would allow children to give a precise number of objects but only for a small number of items (Carey, 2004, 2009). By contrast, the counting procedure can be used to determine a precise number of objects in assigning one number word to each object in the set in one-to-one correspondence respecting the verbal sequence of number words. The counting procedure, which develop as soon as the child acquire the verbal number sequence (i.e., from the age of 2 years, 6 months; Fuson et al., 1982; Gallistel \& Gelman, 1992), is a powerful tool to overcome the limits of the OTS and to determine precisely the exact number of items whatever the size of numbers (Carey, 2004, 2009). Finally, the estimation process would rely on the Approximate Number System (ANS), a core ability thought to be present at birth, which permit children to represent approximately the number magnitudes of sets (Dehaene, 1997; Dehaene \& Changeux, 1993; Stoianov \& Zorzi, 2012; Whalen et al., 1999). This core representational system could be used to apprehend the magnitude of numerosities but with a decreasing precision as the size of the set increases. Later studies supported the use of two different mechanisms dedicated to the processing of small and large numerosities (e.g., Revkin et al., 2008; Sella et al., 2013). This evidence led some authors to consider that the OTS would be automatically implemented whenever the numerosity falls within its limits (Piazza et al., 2002), reserving the use of the ANS to the representation of large numerosities, beyond the subitizing range.

Although there is a general agreement about the existence of these three quantification processes, there is an ongoing debate in the literature about how each of them is involved in the acquisition of number words. Some authors consider the OTS and the counting procedure as the conceptual source of an exact representation of symbolic numbers (i.e., positive integers; Carey, 2004, 2009; Reynvoet \& Sasanguie, 2016; Sarnecka et al., 2015; Sella, Lucangeli, Cohen Kadosh, \& Zorzi, 2020; Sella \& Lucangeli, 2020). Children would start learning to associate number words one by one onto the small numerosities represented with the OTS. Later, through the mastery of the counting procedure, children would figure out the successor function which determine how counting represent numbers. More specifically, they come to understand the order-quantity analogy embedded in the counting sequence, that is, adding one item to a set involve moving to the next number word in the counting list. As there is a change in the representational mechanisms underpinning children's performance in the task, this theoretical position has been called the discontinuity hypothesis. This conceptual shift would lead to the construction of a new, exact representation of symbolic numbers (Carey, 2004, 2009). Other scholars pointed to the ANS as the sole semantic source of symbolic number meaning. In this view, called the continuity hypothesis, numbers words present in the count list would acquire their meanings through a mapping process onto the approximate representation of number magnitude. Subset-knowers would increase the precision of their knowledge of symbolic numbers very gradually, as the precision of the number magnitude representation increases (Cheung et al., 2016; Mussolin et al., 2012; Wagner \& Johnson, 2011 but see Carey et al., 2017; Le Corre \& Carey, 2007; Negen \& Sarnecka, 2015; Odic et al., 2015; Sarnecka \& Lee, 2009 for contradictory evidence and assumption that this mapping could occur later in the development). Finally, other authors consider that all of these mechanisms could contribute to symbolic number acquisition development (Feigenson et al., 2004; Spelke \& Kinzler, 2007).

The last few years, some differences have been reported in the developmental sequence described by Wynn. Some results questioned the number four as the limit at which a generalization process occurs in typically developing children. Several preschoolers were still SS-knowers far beyond four because they knew numbers up to 5, 6, 7, 8 or even 9 but showed no knowledge of the next number words in the GaN task (Krajcsi et al., 2018; Mussolin et al., 2012; Wagner \& Johnson, 2011). Moreover, some preschoolers showed unstable performance for some number words: they

1) Also called "the mental model account." This explanation posit that children has the ability to represent the exact number of elements in small sets via mental models, which involve no numerical representation per se (Huttenlocher et al., 1994; Mix et al., 2002; Simon, 1997). 
exhibited consistent knowledge of small number words, then variable understanding of a range of larger number words and finally, completely no knowledge of the highest number words (Krajcsi et al., 2018). These observations indicate that the limit between known and unknown number words might not be so clear and suggest that the transition between known and unknown numbers is probably more gradual as initially postulated in the knower-level theory. In line with this instability, Wynn (1992) already noticed important differences in the time span of acquisition of number words. The longitudinal examination showed that it would take about a year for one-knowers or two-knowers to become $\mathrm{CP}$-knowers but the data already exhibited important variations in the age of acquisition of cardinal knowledge from one child to another (see also Le Corre \& Carey, 2007; Sarnecka \& Lee, 2009). Indeed, some 3-year-olds were found to be one-knowers when younger children could already be CP-knowers. Since the paper of Wynn (1992), the development of cardinal knowledge has not been tracked in a long-time longitudinal design anymore. Two 6-months follow up studies attempted to document longitudinal changes in verbal number word knowledge in 3 to 5 year-old children but in both studies, about half of the children were already CP-knowers (19/33 in Cheung et al., 2016; 20/42 in Shusterman et al., 2016) and the time window was too short to capture the whole time span of acquisition (8/14 and $7 / 22$ SS-knowers became CP-knowers in Cheung et al., 2016 and Shusterman et al., 2016, respectively)

The differences that have emerged in the literature could be related to important variations in the GaN task methodology. As Wynn (1992), many authors used a titration method consisting of requesting number words in the ascending order, starting with number one, then if successful, two, then three and so on successively. The child was asked for the number $n-1$ in case of failure and $n+1$ in case of success until he/she failed at least two out of three trials for the numerosity $n+1$ and succeeded at least two out of three trials for the numerosity $n$ (Carey et al., 2017; Cheung et al., 2016; Le Corre, 2014; Le Corre et al., 2006; Le Corre \& Carey, 2007; Negen \& Sarnecka, 2012). With this method, proficiency corresponds to the highest number at which the child was at least $66 \%$ accurate. Other studies used a fixed number of trials for each requested number and number words were requested in a random or pseudo random order (Krajcsi et al., 2018; Lee \& Sarnecka, 2011; Piantadosi et al., 2014; Sella \& Lucangeli, 2020; Wagner \& Johnson, 2011).

Another methodological variation relates to the range of assessed numbers with important differences between studies. While Wynn (1992) requested number word until five, other studies went to six (Krajcsi et al., 2018; Le Corre, 2014; Le Corre et al., 2006; Le Corre \& Carey, 2007; Sarnecka et al., 2007; Slusser et al., 2013), seven (Mussolin et al., 2012; Wagner \& Johnson, 2011), eight (Piantadosi et al., 2014; Shusterman et al., 2016), nine (Krajcsi et al., 2018), or ten (Sarnecka \& Lee, 2009; Sella \& Lucangeli, 2020; Wagner \& Johnson, 2011). These studies outlined to importance to test larger number words to be in condition of examining the generalization process.

Finally, a part of the divergences reported between studies could certainly be attributed to more or less subtle differences in the instructions. Some versions of the GaN task include a follow-up question after the child has responded while others do not (Krajcsi et al., 2018; Mussolin et al., 2012; Posid \& Cordes, 2018; Wagner \& Johnson, 2011). Moreover, the follow-up question itself could take different forms with potentially different effects on the performance. In some cases, children were systematically invited to check their answer and recount (Le Corre \& Carey, 2007; Wynn, 1992) or only if they had not counted before (Le Corre et al., 2006; Wynn, 1990) or they were requested to confirm their answer with no incentive to count (“Is that N?" Sarnecka \& Lee, 2009; Shusterman et al., 2016) or, even in some cases, they were prompted to fix their response in case of mismatch between the number of items counted and the requested number word (Le Corre et al., 2006). The rationale behind these questions was that some researchers worried that it did not occur to the children to count even if they understand the way counting represent numbers (Sarnecka et al., 2018). However, as noted by Krajcsi (2021), requesting explicitly to recount the set might hint to the child that he/she might have made a mistake, which could help him/her to correct his/her answer in case of error but might be counterproductive in case of correct answer. Therefore, some subsequent studies took a closer look at how often children fixed their original answer after the question. Sarnecka and Lee (2009) found that the follow-up question had little impact on performance as most children do not change their answer in case of errors while Le Corre et al. (2006) showed that the follow-up question could make a difference for CP-knowers only. Recently, Krajcsi (2021) demonstrated that the follow-up question had a massive influence on performance in the GaN task with higher cardinal knowledge recorded with the Recount instruction compared to the No follow-up question and the Is it N? versions of the task. Interestingly, this effect is caused by a higher proportion of CP-knowers and not by an improved cardinal knowledge in SS-knowers in the Recount condition. These results indicated that the recounting condition was not counterproductive 
but they do not tell whether the recounting instruction improved performance by avoiding performance error or biased the following response by inducing a strategy or both.

The aim of the present study is to provide a conceptual replication of the observations made by Wynn nearly 30 years ago in the GaN task and to provide a clearer picture of the developmental sequence of the cardinal knowledge acquisition in young children. Considering the huge variations of age reported in the acquisition of cardinal knowledge in previous studies, a first cross-sectional study was conducted in a large sample of French-speaking children aged between 39 and 74 months to examine the distribution of cardinal knowledge level across age. With a very small sample size, Wynn (1992) found that children learned small number words one at a time before generalizing their knowledge all-at-once to large number words. However, a different developmental pattern was reported by several authors (Krajcsi et al., 2018; Mussolin et al., 2012; Wagner \& Johnson, 2011). The main goal of the first study was to examine whether the pattern of acquisition described by Wynn (1992) could be replicated in a large sample of children. As a related issue, the influence of age on cardinal knowledge acquisition was examined. According to Wynn (1992), the acquisition of cardinal knowledge would start around the age of 3 years and would reach full maturity 6 months later on average, but subsequent reports depicted a longer period of acquisition extending up to 4 years or more (see Le Corre et al., 2006; Sarnecka \& Lee, 2009). Finally, the strategies used by children were analysed to gain further insight about the underlying mechanisms at work. In a second study, the time span of acquisition of cardinal knowledge was examined in a 16-months longitudinal design in order to track individual developmental sequences in the GaN task. Wynn (1992) estimated that one-knowers or two-knowers spend at least 10 months on average before becoming CP-knowers. However, the time span to get through the successive stages was found to vary considerably from one child to another. In study 2, the time needed for a child to develop full cardinal knowledge and the time spent in each cardinal knowledge level was examined in preschoolers followed longitudinally between the ages of 36 and 52 months.

\section{Study 1: Cross-Sectional Data}

\section{Method}

\section{Sample Size Calculation}

The issues of this cross-sectional study were addressed mainly using descriptive statistics, as was done by Wynn (1990, 1992). To assess the relationship between age and cardinal knowledge development, a priori analysis showed that a minimum of 124 children were necessary to find a correlation of .29 (medium effect size, based on Geary et al., 2019), with significant level of .05 and a statistical power of .95 (Cohen, 1988).

\section{Population}

Two hundred thirteen 3- to 6-year-old children (111 girls - 102 boys) participated in Study 1 (25 3-year-olds, 119 4-year-olds, 63 5-year-olds and six 6-year-olds). The children were recruited from public preschools of the provinces of Brussels, Liege and Walloon Brabant, in the French-speaking part of Belgium. In the sample, 27, 138 and 48 children respectively attended the first year $\left(M_{\text {Age }}=46.1\right.$ months, $S D=6.5$, age range [39-63 months]), the second year $\left(M_{\text {Age }}=\right.$ 54.4 months, $S D=4.9$, age range [39-66 months]) and the third year of preschool $\left(M_{\text {Age }}=68.1\right.$ months, $S D=3.6$, age range [55-74 months]). To participate, parents were sent a written description of the study and signed a written consent form. All children were French-speakers, and none of them were suspected of having learning disabilities, as determined by teacher or parental report. No questions were asked about, race/ethnicity or socio-economic status but children were thought to be representative of the Belgian community from which they were recruited (i.e., low-to-upper income families).

\section{Materials}

The present work focused on the GaN from Wynn's $(1990,1992)$ studies with no intention to test the replicability of results coming from the other tasks (i.e., the Point-to- $x$ task or the colour control task were not administered). However, two additional control tasks were administered to examine whether children could be limited by their knowledge of the verbal number sequence or their mastery of the cardinal word principle in counting (Wynn, 1990). 
Give-a-number task - Unless otherwise mentioned, the GaN task followed essentially the same procedure as the original one described by Wynn (1992) with some adjustments brought by Le Corre and Carey (2007). Fifteen small identical plastic flowers were placed on the table. The experimenter asked the child "Could you give me n flowers?" starting with the number one. As in Wynn's experiments, a titration method was used to determine the highest number word a child succeeded at consistently. With this method, each trial depended partially on the previous one: a child who succeed at giving $n$ was requested $n+1$ the next trial but in case of failure, he/she was requested $n-1$ flowers. Wynn $(1990,1992)$ used two criteria to determine the highest numerosity a child was consistently successful at giving: 1) in at least $2 / 3$ of trials for a numerosity, the child gave the target number according to his own stably ordered counting recitation or the target number \pm 1 (if he counted aloud but double counted or skipped one item) and 2) the child did not give the same number for larger number words more than $50 \%$ as he did when asked for the target number itself. With these criteria, for example, a child who succeeded at least two out of three times at giving one but no more was considered as a one-knower, at giving one and two but no more was considered as a two-knower, and at giving the first four number words but not the fifth were considered as a four-knower. The strategy used by the child to achieve each trial was observed and categorized as counting or grabbing, in accordance with Wynn (1990). The child was considered as counting if he/she manifested at least one of these four behaviors: 1) reciting the counting sequence aloud, 2) pointing each item one at a time, 3) giving items one-by-one, and/or 4) displaying rhythmic nods or finger tapping. In all other cases, the child's procedure was considered as grabbing, consisting generally in giving a handful all at once, as observed by Wynn (1990). The counting/grabbing distinction was coded independently of whether the number given was correct or not.

Unlike Wynn (1990, 1992) who limited her examination to the number word five or six, children could be requested to give up to seven items, a limit falling far beyond the subitizing range, in order to have a wider view on how they generalize their cardinal knowledge to large number words. Importantly, while Wynn $(1990,1992)$ prompted the child to check his/her answer and recount to avoid performance errors, no follow-up question was asked to the child in the present study when he/she gave his/her answer to avoid influencing performance. As discussed by Krajcsi (2021), requesting explicitly to recount the set might bias the performance leading children to exhibit better knowledge than he/she really have. Therefore, a passive version of the GaN task was preferred here. A third methodological difference bear on the scoring criteria as the child's own stable counting sequence was not taken into consideration here (see Le Corre \& Carey, 2007 for similar procedure). However, as did Wynn (1992; Le Corre \& Carey, 2007), one counting imprecision error was admitted and credited as correct, specifically, if the child had made a one-to-one correspondence error in his counting (double counting or skipping one item) resulting in the requested numerosity $n \pm 1$. Finally, a last methodological difference related to the coding of the counting/grabbing strategy. Wynn (1990) considered that giving an incorrect number of items silently, one at a time was grabbing while it was considered as counting here as the accuracy of the answer has not been taken into account.

Verbal number sequence - Children were asked to count as far as possible to assess their knowledge of the counting list. When needed, the recitation was stopped at 20 . The dependent measure was the highest number up to which the child could count correctly, with a maximum limited to 20 .

How many task - The How many task assessed both children's enumeration skills and their knowledge of the cardinal word principle in counting. Children were presented with linear patterns of pictures on a paper and were asked to tell "how many [balls] are pictured on this page?" Four trials were administered including two small numerosities, within the subitizing range ( 2 and 3 items) and two large numerosities (6 and 7 items). An answer was considered as correct when the child gave a cardinal answer to tell how many object (i.e., a last-number word answer). For example, for a pattern of 6 items, children had to say "there are 6" to be credited but counting "one, two, three, four, five, six" without giving a last number word answer was not sufficient. In this last case, the experimenter asked further "could you tell me how many [balls] are there in all?" The dependent measure was the highest number with a correct cardinal word answer in the task. 


\section{Procedure}

The GaN task reported in this paper was part of a larger experimental protocol divided in three parts: the assessment of the cardinal knowledge of number words and number gestures, of fine motor skills and, for some children, pictured arithmetic problems). The order of the parts involving number words and number gestures was counterbalanced to avoid the specific influence of one part on the other or an effect of tiredness. Within the assessment of verbal cardinal knowledge, the tasks were presented in the following order: verbal number sequence recitation, How many task, the Direction task, the GaN task and finally, the Unit task (Sarnecka \& Carey, 2008). The Direction and the Unit tasks were not presented here. Children were tested individually in the morning at school, in a quiet room in one or two testing sessions (maximum 40 minutes by session) depending on children's attentional resources. The testing was suspended as often as the child needed, or when the child exhibited signs of tiredness. The school schedule was always considered.

\section{Results and Discussion}

Preliminary analyses confirmed that all children knew the verbal counting sequence up to larger numbers words than they could give in the GaN task. However, 63 children (29.5\%) could have been limited by their counting mastery in the GaN task as they were not able to count and give a cardinal answer for higher numbers in the How Many task than in the GaN task. To avoid the potential bias of removing the least capable counters on the basis of a variable (How many task) that is not independent of the variable of interest $(\mathrm{GaN})$, all children were included in the subsequent analyses. Table 1 reports the proportion of children who were not limited by their counting mastery for each cardinal knowledge level.

\section{Table 1}

Distribution of Children in Each Cardinal Knowledge Level, Descriptive Information About Their Age and Their Preschool Academic Levels, and the Proportion of Children Not Restricted by Their Counting Level

\begin{tabular}{|c|c|c|c|c|c|c|c|}
\hline \multirow[b]{2}{*}{ Cardinal Knowledge Level } & \multirow[b]{2}{*}{$N$} & \multicolumn{2}{|c|}{ Age } & \multirow{2}{*}{$\begin{array}{l}\text { Children Not Limited by } \\
\text { Their Counting Level }^{\mathrm{b}}\end{array}$} & \multicolumn{3}{|c|}{ Preschool Level } \\
\hline & & $M$ & Range & & 1 & 2 & 3 \\
\hline Pre-numeral knowers & 2 & $55.0(6.4)$ & $51-60$ & $2(100 \%)$ & 1 & 1 & 0 \\
\hline \multicolumn{8}{|l|}{ Small } \\
\hline SS-knowers & 60 & $51.3(6.1)$ & $39-64$ & $54(90 \%)$ & 15 & 44 & 1 \\
\hline One & 5 & $56.0(5.9)$ & $49-64$ & $4(80 \%)$ & 0 & 5 & 0 \\
\hline Two & 32 & $49.8(6.1)$ & $39-59$ & $30(93.8 \%)$ & 12 & 19 & 1 \\
\hline Three & 23 & $52.3(5.5)$ & $39-60$ & $20(87 \%)$ & 3 & 20 & 0 \\
\hline \multicolumn{8}{|l|}{ Large } \\
\hline SS-knowers & 52 & $56.1(7.9)$ & $39-71$ & $38(73 \%)$ & 4 & 39 & 9 \\
\hline Four & 25 & $53.0(6.4)$ & $39-69$ & $17(68 \%)$ & 2 & 22 & 1 \\
\hline Five & 12 & $58.8(9.2)$ & $39-70$ & $10(83.3 \%)$ & 2 & 6 & 4 \\
\hline Six & 15 & $59.1(7.6)$ & $49-71$ & $11(73.3 \%)$ & 0 & 11 & 4 \\
\hline Max-knowers $^{\mathrm{a}}$ & 99 & $59.8(8.3)$ & $39-74$ & $67(67.7 \%)$ & 7 & 54 & 38 \\
\hline Total & 213 & $56.4(8.4)$ & $39-74$ & $150(70.4 \%)$ & 27 & 138 & 48 \\
\hline
\end{tabular}

Note. SS = Subset. Age is reported in months. Standard deviations are shown in parentheses. Level 1, 2, and 3 correspond to the first, second, and third academic year of preschool.

a Seven-knowers.

bProportion of children who could count and give a cardinal response for higher numbers in the How Many task than in the GaN task.

A first goal of this study was to examine the distribution of cardinal knowledge levels and the influence of age. As shown in Table 1, two children ( $0.9 \%$ of our sample) did not know the cardinal meaning of any number words (considered as pre-numeral-knowers). In the small number range, five children were one-knowers (i.e., $2 \%$ who knew only the cardinal meaning of the word "one"), 32 were two-knowers (15\%) and 23 were three-knowers (10.8\%). In reference to the 
classification used in Krajcsi et al. (2018), these children will be considered as Small-numbers SS-knowers, to be compared with the Large-numbers SS-knowers which included 25 four-knowers (11.7\% who knew the cardinal meanings up to "four" but no more), 12 five-knowers (5.6\%), 15 six-knowers (7\%). Finally, 99 children mastered the cardinal meanings of all the number words they were asked for and, were very likely to be CP-knowers (46.5\%) in accordance with Wynn's criteria. However, some of these children could still remain seven-number SS-knowers and not be really CP-knowers. For the sake of cautiousness, they were called Maximum-number knowers (Max-knowers) to outline the limit of the number range under consideration here.

Based on her data, Wynn $(1990,1992)$ assumed that children learned the cardinal meanings of small numbers sequentially and then, generalize their cardinal knowledge all-at-once to all number words within their counting range. However, in the present sample, 52 preschoolers were Large-numbers SS-knowers, indicating that they knew the cardinal meanings of number words up to 4, 5 or 6 but not of all number words within their counting list. Interestingly, of the 52 children, 38 could give a last-word cardinal answer up to larger number words in the How many task. There were thus not limited by their enumeration skills nor their understanding of the cardinal principle in counting. Actually, 151 children had a cardinal level higher than 3 and would have been considered as CP-knowers within the limits of Wynn's experiments (as they mastered the cardinal meanings of large number words). However, only $65.6 \%$ of them were successful at giving all requested number words while $34.4 \%$ showed only partial cardinal knowledge of large numbers. This observation questioned Wynn's assumption according to which children would generalize all-at-once their cardinal knowledge acquired on small number words to large number words. Children seems to learn the cardinal meanings of number words sequentially, not only for small numbers, but also for large numbers within their counting list. Even in the present study, assimilating seven-knowers to CP-knowers is an interpretation that should be taken cautiously. As the task stopped at the number seven, there is actually no clue to consider that they had generalized their cardinal knowledge to larger numbers within their counting list. Using higher number words in this task, the 99 seven-knowers could have been split in other knowledge level subgroups (eight-knowers, nine-knowers or ten-knowers for example). These results support Krajcsi et al.'s (2018) suggestion of a reevaluation of the widely acknowledged seizure between SS-knowers and CP-knowers around 3 or 4.

Table 1 confirmed the great variability in the age of acquisition for each level of cardinal knowledge as attested by the wide age range and the standard deviation ranging between 6 and 10 months around the mean age. Cardinal knowledge level was correlated with the age of children, as confirmed by the significant correlation between age (in months) and performance in the GaN task $\left(r_{\text {Spearman }}=.42, p<.001\right)$. This is accordance with the effect of age reported by Wynn (1992) who found younger children in smaller cardinal knowledge groups (one-, two- and three-knowers) and older children belonging to CP-knowers group. Interestingly, however, considering separately children with cardinal knowledge of small versus large number words (i.e., 62 children with cardinal knowledge from 0 to 3 versus 151 cardinal knowledge from 4 to 7) yielded divergent pattern of correlation. For children with small numbers knowledge, the correlation between age and cardinal knowledge level was not significant $\left(r_{\text {spearman }}=-.001, p>.05\right)$, indicating no relation between the age of children and their cardinal knowledge of small number words. By contrast, a significant correlation was found between age and cardinal knowledge level for children with large number cardinal knowledge $\left(r_{\text {Spearman }}=.249, p<.002\right)$, suggesting that children keep on developing their cardinal knowledge with age even in the range of large number words.

Wynn also found that, by the age of $3 \frac{1}{2}$ years, most of children mastered the cardinal meanings of all number words within their counting list. Figure 1 displays for each age group, the percentage of children belonging to each cardinal knowledge level (see Table A1 for a detailed distribution of children in each cardinal knowledge level with a standard time span of 4 months). A first observation that stood out of the distribution of frequencies is the wide diversity of cardinal knowledge profiles in 3-, 4- and 5-year-olds. Most 4-year-old children were still SS-knowers (75/119). Interestingly, $85 \%$ of them were not limited by their counting skills in the range of large numbers (64/75 SS-knowers were either Small-number SS-knowers or reached higher numbers in the How many task). Actually, the vast majority only started to master all numbers presented in the task between the age of 4 and 6 years. Between the age of 4 and 5 years, about half of the children (48\%) were still 2-, 3- or 4-knowers. In the age range between 5 and 6 years, while a majority of children reached the maximum number knowledge group, about one third of them (33\%) still exhibited partial cardinal knowledge of the numbers used in the task. 


\section{Figure 1}

Percentage of Children Belonging to Each Cardinal Knowledge Level for Each Age Group

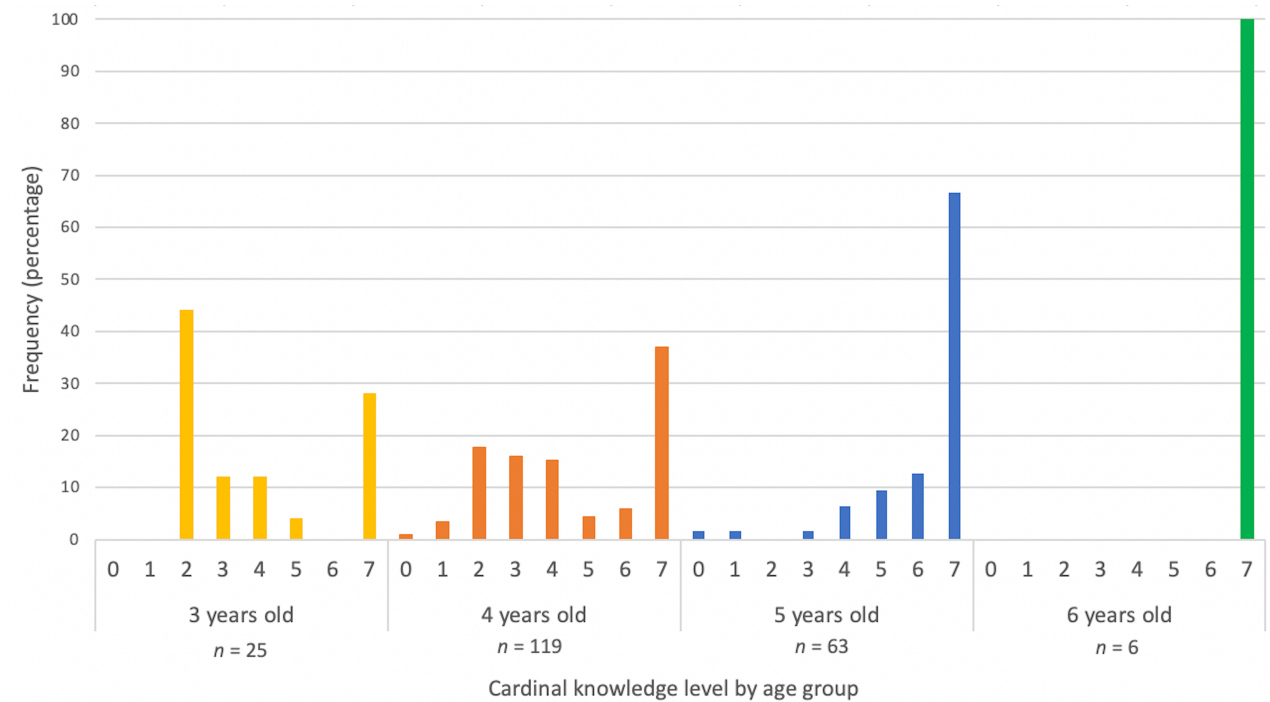

As reported by Wynn (1990), another informant observation about children's understanding of the cardinal value of number words comes from the distinction between grabbers and counters. Wynn predicted that SS-knowers should make a more extensive use of the grabbing strategy for giving numbers whatever their size but that CP-knowers -who presumably understand how counting represent numbers- should make a more frequent use of counting for large numbers compared to small ones, which could be succeeded using subitizing. The strategy used by children were recorded on all attempted trials (succeeded or failed) ${ }^{2}$ for number words smaller (two and three) and larger than four (five, six and seven). The number four, being at the limit of the small and large number ranges, was not included in either of these categories in the subsequent analysis. Figure 2 represent these data separately for children who would have been considered by Wynn as SS-knowers (i.e., Small-numbers SS-knowers: 2- and 3-knowers) and CP-knowers (i.e., Large-numbers knowers: 4-, 5-, 6- and 7-knowers). Due to the titration method, Small-numbers SS-knowers did not attempted any trials on large number words, which preclude the comparison of the counting/grabbing ratio in Small numbers SS-knowers. For information, with regards to small number words, there was no difference between Small- and Large-numbers knowers in the frequency of counting/grabbing strategies. $\left(\chi^{2}=2.90, p=.09\right)$. By contrast, Large-numbers knowers used counting more frequently for large number words than for small ones $\left(\chi^{2}=6.40, p=.01\right)$, in accordance with Wynn's predictions. Note that the proportion of grabbing for giving large numbers remained high even in Large-numbers knowers. 


\section{Figure 2}

Frequency of Counting/Grabbing Strategies on All Attempted Trials for Number Words Smaller and Larger Than Four Separately for Small- Versus LargeNumbers Knowers

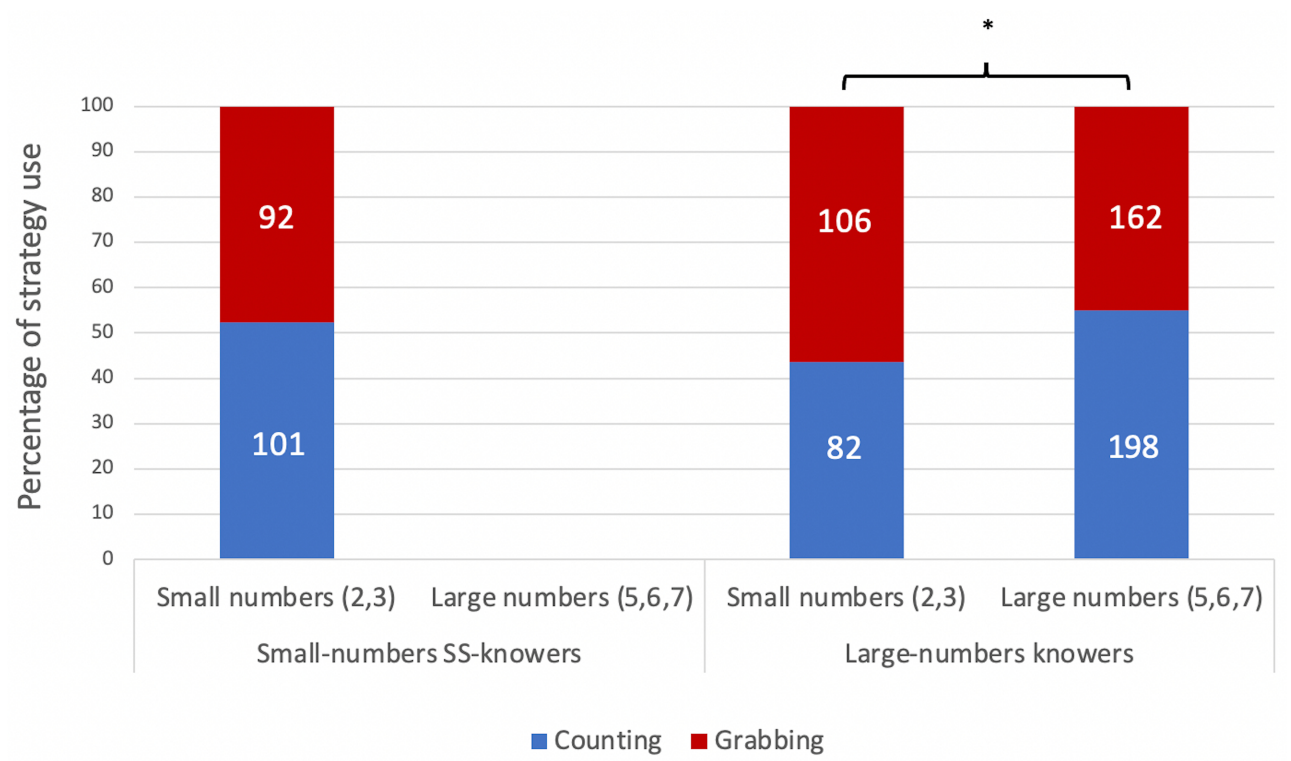

Note. Small-numbers SS-knowers encompassed knower-level $<4$; Large-numbers-knowers encompassed knower level $\geq 4$ including Max-number knowers.

The high rate of success for grabbers in the range of large number words suggested that some children kept on using this strategy for all trials whatever the size of the requested numbers. This observation questioned the strategy consistency along the task: if counting is the best strategy to achieve higher levels of cardinal knowledge, consistent counters should achieve higher levels of cardinal knowledge as well as those who switched from a grabbing to a counting strategy between the range of small and large number words. The strategies could have been recorded all along the task in 147 children from our sample to determine their strategy profile. Table 2 reported the number of consistent counters, consistent grabbers or children who exhibited a mixt profile (i.e., children who switched of strategies during the task) ${ }^{3}$ depending on the range of their cardinal knowledge (i.e., Small- vs. Large-number knowledge). Hundred eighteen children were very consistent in their strategies (79.7\%) while 29 children presented a mixed profile $(24.6 \%)$. Interestingly, the majority of them switched from a grabbing to a counting strategy (24/30-80\%). Moreover, among the children who switched from a grabbing to a counting strategy, the switch occurred mainly between 3 and 5 (i.e., 15/24). Conversely, $17.2 \%$ switched from a counting to a grabbing strategy (5/29) and all of them started grabbing at 3. If counting is indeed a more efficient tool to determine the cardinal of large number words, then, using counting, especially when the number of items increased (i.e., consistent counters or children who switched from a grabbing to a counting strategy; here called terminal-counters, $n=91$ ) should provide an advantage to reach higher levels of cardinal knowledge compared to those who used grabbing in this range (i.e., consistent grabbers or children who switched to a grabbing strategy; here called terminal-grabbers, $n=56$ ). However, the proportion of children who reached large number cardinal knowledge, did not differ between terminal-counters (58/91-63.7\%) and terminal-grabbers $\left(36 / 56-64.2 \% ; \chi^{2}=\right.$ $0.005, p>.05)$. Thus, in the present study, the categorization of children according to their profile of consistent counters or their ability to switch to a counting strategy in the range of large number words was not so relevant to account for the distinction between Small- and Large-number-knowers.

3) Note that one child switched twice: once from counting to grabbing at giving 3 and once from grabbing to counting at giving 5 . He was thus counted twice. He was not considered in the final count here. 
Table 2

Number of Consistent Counters, Consistent Grabbers or Children Who Exhibited a Mixt Profile Depending on Their Cardinal Knowledge Level

\begin{tabular}{|c|c|c|c|c|c|}
\hline \multirow[b]{2}{*}{ Knowledge-Level } & \multirow[b]{2}{*}{$N$} & \multicolumn{2}{|c|}{ Consistent profile } & \multicolumn{2}{|c|}{ Mixt profile } \\
\hline & & Counters & Grabbers & $\mathrm{G}$ to $\mathrm{C}$ & $C$ to $\mathrm{G}$ \\
\hline$<4^{\mathrm{a}}$ & 53 & 29 & 17 & 4 & 3 \\
\hline$\geq 4^{\mathrm{b}}$ & 94 & 38 & 34 & 20 & 2 \\
\hline
\end{tabular}

Note. $\mathrm{C}=$ Counting; $\mathrm{G}=$ Grabbing.

${ }^{a}$ Knower level $<4$ encompassed Small-numbers SS-knowers.

${ }^{b}$ Knower level $\geq 4$ encompassed Large-numbers-knowers including Max-number knowers.

Finally, to uncover the mechanism underlying the grabbing strategy in SS-knowers, grabbing responses beyond the child level of knowledge were more closely examined. Given the imprecision of the ANS, three behavioral signatures are considered as key evidence of the involvement of approximate number representation in estimation task. The two first bear on the mean estimates and the standard deviations of the estimates which should increase with the size of the target number (i.e., scalar variability). This result in a third parameter, the coefficient of variation (COV), which should remain constant across requested number. However, due to the titration method, all participants were not presented with every number word under consideration here. As a result, individual slope based on mean responses, standard deviations, and COVs as a function of the target number word could not be computed for each participant as was done in other studies (Gunderson et al., 2015; Wagner \& Johnson, 2011; Wagner et al., 2019). Nevertheless, to examine whether an ANS-based estimation strategy could have been implemented by SS-knowers for giving numbers beyond their levels of proficiency, mean, standard deviations and COVs were calculated for each requested number word on all occurrences of grabbing errors beyond the child level of knowledge $(\mathrm{KL}+1) \cdot{ }^{4}$ As can depicted on Figure 3, the mean number of items given in case of grabbing errors showed a positive slope of .60, indicating that number of items given increases with the size of the requested number. However, the slope of standard deviations as a function of the target number was negative and close to 0 (slope coefficient $=-.007$ ) while the slope of COVs showed a downward sloping trend with a coefficient of -.035 , which is not consistent with the implementation of an ANS estimation strategy for grabbing responses beyond the child level of proficiency. Yet, as we could not make a $t$-test to determine whether the slopes significantly differ from 0 , these observations were reported for information purpose only.

To sum up, contrasting with Wynn's assumptions, most of $3 \frac{1 / 2}{2}$ year-old children did not master the cardinal meanings of all number words within their counting list. The huge majority started to master all numbers presented in our task between the age of four and six years. Wynn (1992) observed that Small-numbers-knowers encompassed younger children while Large-number knowers included older children. The present data yielded a similar developmental pattern but the influence of the age was significant only for large-number knowers, supporting the view that children continue to develop their cardinal knowledge with age even for large number words. Indeed, the present results showed that children learn number words sequentially even for large-number words within their counting list. These results are in line with previous study showing that several preschoolers knew a subset of large number words (beyond 4) without having generalized their knowledge to all numbers within their counting range and could not be considered as CP-knowers (Krajcsi et al., 2018; Mussolin et al., 2012; Wagner \& Johnson, 2011). A generalization probably occurs at some point in the development but not necessarily after having demonstrated cardinal knowledge of small number words. Moreover, in accordance with Wynn (1992) and other authors (i.e., Le Corre \& Carey, 2007; Sarnecka \& Lee, 2009), a large variability in age was found for each cardinal knowledge level.

4) Note that no grabbing correct response was recorded beyond children's knower level. Therefore, the analyses focused on grabbing errors beyond the child level of proficiency $(\mathrm{KL}+1)$. 


\section{Figure 3}

Mean Number of Items Given, Standard Deviations and Coefficient of Variation on Grabbing Errors as a Function of Requested Number Beyond a Child's Knower Level for Requests of 3 to 7 Items

Mean number given

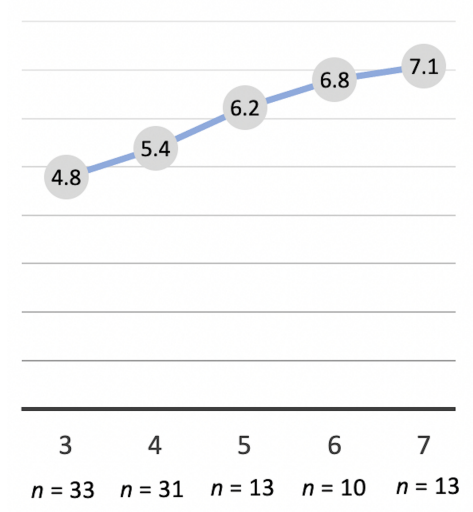

Standard Deviations
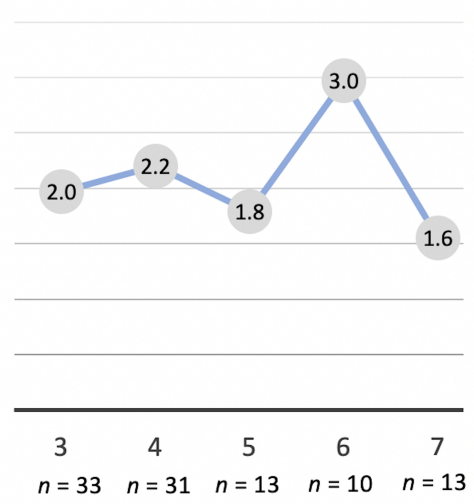

Requested Number (KL+1)
COVs (SD/Mean)

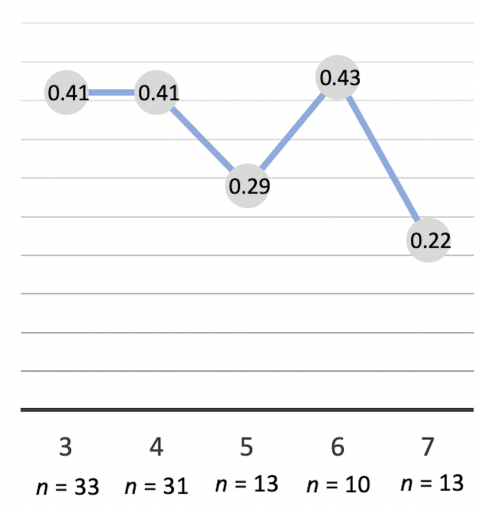

The distinction between counting and grabbing strategies showed that Large-number SS-knowers (i.e., considered as CP-knowers by Wynn) made a more extensive use of counting to give large number words, as predicted by Wynn. Yet, a about half of them succeeded at giving large number words without implementing an observable counting strategy. Additionally, the majority of participants kept on using the same strategy to give small and large numbers providing limited evidence for a shift in the quantification procedure underlying the access to higher level of cardinal knowledge. Interestingly, some children switched from a grabbing to a counting strategy as observed by Wynn. This change occurred principally between 3 and 5. However, being a terminal-counter (i.e., either a consistent counter or switching to counting in the range of large numbers) made no difference for accessing to the cardinal meanings of larger number words compared to terminal-grabbers. Indeed, many trials were succeeded using a grabbing strategy in the large number range.

About the mechanism underlying the grabbing strategy, a closer look at the distribution of grabbing responses/errors revealed no signs of scalar variability as would be expected with the use of ANS-based estimation strategy. This result is consistent with Lee and Sarnecka (2011) who convincingly demonstrated using Bayesian analyses that the knower-level model better fitted the distribution of responses in the GaN task compared to the ANS account. But how could children capture the precise meaning of large number words -hence reaching large-numbers knowledge levelsusing grabbing, an inherently approximate strategy? One plausible account is that some children use a mix of exact number processing strategies combining subitizing small subsets and addition. Several pieces of evidence indeed showed that young children start being able to perform small nonverbal addition problems with no counting possibility (as items are occluded) around the age of 4 years onwards (Huttenlocher et al., 1994; Sarnecka \& Carey, 2008; Schneider, Pankonin, Schachner \& Barner, 2021, see also Secada et al., 1983 for counting on ability with large numbers in 6 year-old children). This evidence leaves open the possibility that children could have subitized a first subset of items and then silently counted on from the first subset to reach the requested number with no apparent sign of one-by-one processing (i.e., a condition for a trial to be classified as counting in the present experiment).

Finally, it is noteworthy that many children used counting even for small numbers, indicating that they rely neither on the OTS nor on the ANS in the small number range. This could result from the fact that children are regularly prompted to use counting in numerical context in preschool settings or at home, leading them to develop a counting habit in the face of a number-related request. Another possibility is that they decide to adopt a counting strategy rather than an OTS-based grabbing strategy because they care about giving the correct response and they already understand that counting is an efficient tool to determine precisely the number of items whatever their size. In this case, the 
strategy choice would reflect a higher level of confidence in the counting strategy rather than the implementation of a cognitive mechanism.

In Study 1, the cross-sectional data outlined the important variability in the age of acquisition of number words cardinal meaning. However, within-subject exploration would be necessary to examine the time span of acquisition cardinal knowledge. In particular, how long does it take for a child to develop full cardinal knowledge and how long is the time spent in each cardinal knowledge level. These issues will be addressed in Study 2 using a longitudinal design.

\section{Study 2: Longitudinal Data}

\section{Method}

\section{Sample Size Calculation}

The issues of this longitudinal study were addressed mainly using descriptive statistics, as was done by Wynn (1992). In order to track the effect of age (within-subject factor, 5 time points) using a repeated measures ANOVA, a priori analysis showed that a minimum of 32 children are sufficient to find a small effect size of .20 with significant threshold of .05 and a statistical power of .80 (Cohen, 1988).

\section{Population}

Thirty-four children (17 girls - 17 boys) participated in this longitudinal study. At the beginning of the study, their age was exactly 3-year-old (36.0 \pm 0.0 months). Children were recruited in kindergarten schools in the provinces of Brussels, Liege and Walloon Brabant, in Belgium. To participate, parents were sent a written description of the study and signed a written consent form. All children were French-speakers, as determined by teacher or parental report. No questions were asked about race/ethnicity or socio-economic status but children were thought to be representative of the Belgian community from which they were recruited (i.e., low-to-upper income families).

\section{Materials and Procedure}

Children were tested five times every four months for a period of 16 months using the GaN task (maximum 2 weeks around the day of their 36, 40, 44, 48 and 52 months). The task procedure, the material, the scoring criteria were exactly the same as in Study 1.

\section{Results and Discussion}

The aim of the Study 2 was to assess the time needed for a child to develop full cardinal knowledge and the time spent in each cardinal knowledge level. A first way to estimate the time span of acquisition of cardinal knowledge is to examine the repartition of children according to their cardinal knowledge level at each test session. As depicted in Table 3 and in accordance with Study 1, most of children were Small-numbers SS-knowers up to 40 months. At 44 and 48 months, none of the children mastered the cardinal meanings of all number words in the task. Unlike Wynn (1992) who found that most children became CP-knowers around the age of $3 \frac{1}{2}$ years (42 months), children from the present sample seem to acquire cardinal knowledge much slower. These differences might reflect socio-demographics (i.e., age, SES), linguistic or cultural differences between the current sample and those of Wynn's $(1990,1992)$ studies. It could also be due to the small methodological variations including the examination of larger number words (leaving open more possibilities to observe an inequal acquisition of number words cardinal meaning beyond four) or the absence of any follow-up questions prompting the child to count and make sure. Actually, more than half of the children (19/34) were still Small-numbers SS-knowers at 44 months, suggesting that cardinal knowledge development spread out over a much more extended period than expected on the basis of Wynn's original investigations. Furthermore, it confirmed the assumption of Study 1 that children keep on learning the cardinal meanings of large number words sequentially and do not necessarily generalize all-at-once the knowledge acquired on small numbers to large number words. 
Table 3

Distribution of Children in Each Cardinal Knowledge Level as a Function of Age

\begin{tabular}{|c|c|c|c|c|c|}
\hline Cardinal Knowledge Level & 36 Months & 40 Months & 44 Months & 48 Months & 52 Months \\
\hline Pre-numeral-knowers & 4 & 0 & 0 & 0 & 0 \\
\hline Small numbers SS-knowers & 29 & 30 & 19 & 11 & 5 \\
\hline One-knowers & 6 & 3 & 2 & 0 & 0 \\
\hline Two-knowers & 17 & 18 & 9 & 5 & 3 \\
\hline Three-knowers & 6 & 9 & 8 & 6 & 2 \\
\hline Large numbers SS-knowers & 1 & 4 & 15 & 23 & 9 \\
\hline Four-knowers & 0 & 2 & 4 & 8 & 3 \\
\hline Five-knowers & 1 & 2 & 11 & 15 & 3 \\
\hline Six-knowers & 0 & 0 & 0 & 0 & 3 \\
\hline Maximum numbers knowers & 0 & 0 & 0 & 0 & 20 \\
\hline
\end{tabular}

Note. SS-knowers = subset knowers.

Another way to assess the time needed for a child to develop full cardinal knowledge and the time spent in each cardinal knowledge level is to examine how children develop their cardinal knowledge as a function of their initial level of knowledge. Figure 4 reported individual developmental trajectories of cardinal knowledge as a function of children's cardinal knowledge at 36 months (see Table A2 for a detailed evolution of children through knower-levels according to their initial level of cardinal knowledge). Except for the child who was already a five-knower at 36 months, all other children exhibited a progressive evolution of their cardinal knowledge throughout the next 16 months. All pre-numeral-knowers rapidly became Small-numbers SS-knowers after 4 months and most of pre-numeral- and one-knowers stayed at this stage for 12 months before becoming Max-knowers 16 months later. Most two-knowers became Large-numbers SS-knowers after 12 months while three- knowers mainly reached this stage quite earlier after 8 months. Even after 16 months, barely 54\% of two- and three-knowers taken as a group (i.e., 9/17 and 3/5, respectively) mastered all the number words requested in the task. Thus, the initial level at 36 months yielded small differences in the cardinal developmental trajectories during one year (with a slight advantage for children starting with more advanced cardinal knowledge) but these differences fade later. These results highlighted the progressive evolution of children throughout the testing sessions and provide support for Wynn's assumption of highly variable time span of acquisition from one child to another.

As observed in the Study 1 with cross-sectional data, the mean age increased along with cardinal knowledge level, $F(4,132)=84.16, p<.001$. One outstanding issue concerned the age at which each cardinal knowledge level was reached. As children were tested every four months, for some children, the specific moment at which each level was reached could have been missed (for instance when a child jumped more than one level between two time points of testing). Table 4 thus displays the mean age at which each cardinal knowledge level was reached, based on all observable occurrences of change identified across all time points of testing. The mean age of Small-numbers SS-knowers was on average 3 years and 8 months while Large-numbers SS-knowers were on average 4-year-old. The mean age grew constantly with more advanced cardinal knowledge. As displayed in Table 4, the higher the cardinal knowledge level, the narrower was the age range. 


\section{Figure 4}

Individual Cardinal Knowledge Development as a Function of Their Initial Cardinal Knowledge Level
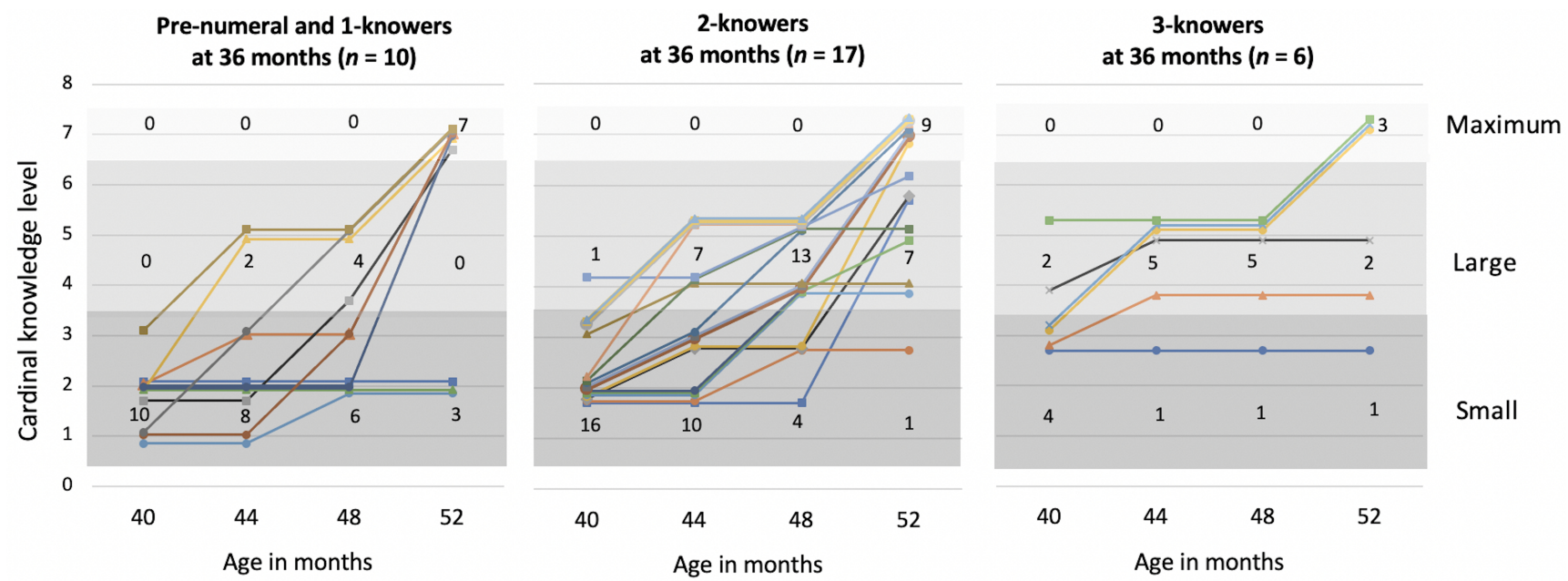

Note. This Figure represents the children's individual developmental trajectories of cardinal knowledge as a function of their initial cardinal knowledge level (at 36 months). The frequencies were reported in the graph to indicate the number of children who achieved small, large, and maximum level of cardinal knowledge after 4, 8, 12 and 16 months respectively.

Table 4

Mean Age at Each Cardinal Knowledge Level

\begin{tabular}{lccc}
\hline & & & Age \\
\cline { 3 - 4 } Cardinal Knowledge Level & $\boldsymbol{N}^{\mathrm{a}}$ & $\boldsymbol{M}$ & Range \\
\hline Pre numeral-knowers & 4 & 36 & - \\
\hline Small numbers SS-knowers & 47 & $44.1(4.9)$ & $36-52$ \\
$\quad$ One-knowers & 6 & $39.3(3.9)$ & $36-44$ \\
$\quad$ Two-knowers & 24 & $42.2(5.1)$ & $36-52$ \\
$\quad$ Three-knowers & 17 & $44.0(4.7)$ & $40-52$ \\
\hline Large numbers SS-knowers & 30 & $48.0(4.2)$ & $44-52$ \\
$\quad$ Four-knowers & 11 & $47.6(3.8)$ & $44-52$ \\
$\quad$ Five-knowers & 16 & $49.0(1.6)$ & $48-52$ \\
\hline Mix-knowers & 3 & $52.0^{\mathrm{b}}$ & $52.0^{\mathrm{b}}$ \\
\hline
\end{tabular}

Note. Age is reported in months. Standard deviations are shown in parentheses.

${ }^{a}$ Number of observable occurrences of change across all time points of testing.

${ }^{b}$ The age limit of the longitudinal examination.

A last issue related to the mean time necessary to acquire new cardinal knowledge. Table 5 reported the mean time necessary to move from one cardinal knowledge level/category to the next one, based on all observable occurrences of change identified across all time points of testing. Children took on average 6 months to move from one cardinal knowledge level to the next one and between 5 and 8 months on average to move from one cardinal knowledge category to next one. However, there was large differences between the fastest and the slowest child to move from one cardinal knowledge level to the next one (i.e., between 4 and 16 months.) or to move from one cardinal knowledge category to more advanced category of knowledge (between 4 and 12 months to move Small numbers SS-knowers to Large numbers SS-knowers and between 4 and 16 months to move from Large numbers SS-knowers to Maximum numbers knowers). 
Finally, the time needed for a child to develop full cardinal knowledge varied depending on their cardinal knowledge at the initial state. It took about 16 months for Prenumeral-knowers to acquire the cardinal knowledge of all number words under consideration in this experiment. Naturally, this period of time was reduced for children who already had some cardinal knowledge (i.e., around 9 months for Small numbers SS-knowers and 8 months for Large numbers SS-knowers).

Table 5

Mean Time Spent to Move From One Cardinal Knowledge Level to Another One

\begin{tabular}{|c|c|c|c|}
\hline \multirow[b]{2}{*}{ To move ... } & \multirow[b]{2}{*}{$N^{\mathrm{a}}$} & \multicolumn{2}{|c|}{ Time span } \\
\hline & & $M$ & Range \\
\hline$\ldots$ From one cardinal $\mathrm{KL}$ to $\mathrm{KL}+1$ & 17 & $6.58(3.1)$ & $4-16$ \\
\hline ... From Small- to Large-numbers KL & 22 & $5.5(2.6)$ & $4-12$ \\
\hline ...From Small- to Max-numbers KL & 17 & $8.9(3.3)$ & $4-12$ \\
\hline ...From Large- to Max-number KL & 11 & $8.0(3.1)$ & $4-16$ \\
\hline
\end{tabular}

Note. $\mathrm{KL}=$ knowledge level. Time span is reported in months. Standard deviations are shown in parentheses. Based on observable occurrences of change across all time points of testing.

\section{General Discussion}

The aim of the present study was to provide a conceptual replication of Wynn's experiments conducted nearly 30 years ago to characterize the sequence of cardinal knowledge development. Study 1 presented cross-sectional data collected in a large sample of French-speaking children aged between 39 and 74 months using the GaN task, the original task designed by Wynn. In Study 2, the time span of cardinal knowledge acquisition was examined within a longitudinal design in which children were tested five times (once every four months) between the age of 36 and 52 months.

The first objective was to examine how children acquire the cardinal meanings of number words. In a small sample of children, Wynn (1992) found that children learn the cardinal meanings of small number words one at a time before generalizing simultaneously their knowledge to large number words, a learning pattern that has been widely supported by other findings (Le Corre et al., 2006; Le Corre \& Carey, 2007; Negen \& Sarnecka, 2012; Sarnecka \& Carey, 2008; Sarnecka \& Gelman, 2004; Sarnecka \& Lee, 2009; Slusser et al., 2013; Slusser \& Sarnecka, 2011). Based on a large sample of children, the present data rather suggest that children learn number words sequentially, one after the other, not only for small number words but also for number words larger than three or even four. In both studies, a significant proportion of children exhibited partial cardinal knowledge of large number words and mastered only the first four, the first five, or the first six number words but failed at giving larger numbers. Moreover, the correlation between age and cardinal knowledge was significant only for children with large numbers knowledge and not for Small-numbers SS-knowers, indicating that children keep on gaining cardinal knowledge of large number words with age. Altogether, these data questioned the assumption that children would generalize all-at-once to larger number words, the cardinal knowledge they learned on small number words. In keeping with previous studies, some preschoolers were found to know the meanings of number words beyond 4 while they did not yet achieve the semantic induction leading them to access the cardinal meanings of all numbers in their counting list (Krajcsi et al., 2018; Mussolin et al., 2012; Wagner \& Johnson, 2011). Therefore, these children had still to be considered as SS-knowers and not automatically as CP-knowers when reaching number five or six. At some point in their development, children presumably generalize the cardinal knowledge accumulated to all number words within their counting list, but probably at different level of cardinal knowledge and, for the vast majority of them, not as early as they have learned the meanings of small number words.

Furthermore, Wynn's (1992) observations suggested that the access to higher level of cardinal knowledge would be related to their ability to use counting. For Wynn, the distinction between counters and grabbers provided interesting information about children's understanding of the cardinal value of number words, and would be the key accounting for the difference between SS- and CP-knowers. Supporting this view, Large-numbers knowers (4- to 7-knowers) were found to be more likely to resort to counting for large number words than for small ones in study 1 . In addition, several 
children switched from a grabbing to a counting strategy around four. However, the majority of participants kept a consistent strategy all along the task and many of them still succeeded at giving large numbers with a grabbing strategy. Thus, the strategy, at least as coded here, could not be considered as what makes the difference to acquire the cardinal knowledge of large number words.

The present findings provide limited clues about the mechanisms underlying the cardinal knowledge acquisition. On one hand, the significant number of Large-numbers SS-knowers obscured the boundary between the acquisition of small and large number words. At first glance, the absence of clear distinction in the pattern of acquisition of small and large number words is inconsistent with the discontinuity hypothesis which assumed the involvement of different mechanism/representation on both sides of this limit, namely, the OTS for learning small number words, and the counting procedure for determining the meanings of large number words (Carey, 2004, 2009; Reynvoet \& Sasanguie, 2016; Sarnecka et al., 2015). In addition, most children preferred using the same strategy all along the task and only one out of five children exhibited a shift from a grabbing to a counting strategy around the number four as would have been expected under the discontinuity hypothesis. On the other hand, the present data do not support the continuity hypothesis either as the grabbing errors beyond children's knower level exhibited no sign of the implementation of an ANS-based estimation strategy. Interestingly, many children used counting all along the tasks, even for small numbers. If the use of counting reflects their level of confidence in this strategy to fulfill the objective of the task, it marks a beginning of understanding of the way counting represent numbers, even if they are not yet CP-knowers. By contrast, other children showed no apparent signs of counting even to give large number words, suggesting that they might use a subitizing/addition combination. Thus, the GaN task turned out to be achieved in very different ways using different representational mechanisms depending on child's variables, and notably, his/her understanding of the way counting is relevant to address numerical content.

Altogether, the current data leaves open many possible interpretations about the mechanism underlying cardinal knowledge acquisition, including the possibility that different representations/mechanisms (i.e., at least OTS and counting) could contribute, in variable proportions depending on the age, to the acquisition of number words meanings (Feigenson et al., 2004; Spelke \& Kinzler, 2007). In particular, the present findings did not to provide conclusive evidence about the mechanisms (i.e., counting, grabbing, approximating, multiple subitizing and grouping) for being a large-number knower (5-, 6- or 7-knowers) but not a CP knower. Crucially, we need to go beyond the simple counting/grabbing dichotomy to enable a finer-grained coding of the strategies used by the child to solve the task. The mechanism(s) underlying the grabbing strategy in the range of large number words would deserve further attention in the future. Moreover, further studies are necessary to deepen our understanding of the conceptual source of cardinal knowledge. In the mapping process between ordinal and quantitative information embedded in the verbal number sequence, the position of number word in the counting list (in particular, the knowledge of the predecessor) has been identified as a main conceptual source in comparing the cardinal meaning of verbal number words (Sella \& Lucangeli, 2020; Sella et al., 2020). Future works should focus more specifically on this issue to gain further knowledge about the root of numerical symbol acquisition (see Reynvoet \& Sasanguie, 2016 for a review).

A second issue concerned the age of acquisition of cardinal knowledge. Wynn (1992) claimed that children become CP-knowers around 3 1/2 year-old (42 months) and reported an effect of age suggesting that younger children exhibit lower level of cardinal knowledge (one-, two- and three-knowers) than older children. A similar correlation between age and cardinal knowledge was indeed observed in Study 1 . However, convergent observations from Study 1 and 2 indicates that cardinal knowledge were far from achieving maturity at the age of $31 / 2$ years. Study 1 showed that most 4-year-old children did not master the cardinal meanings of all number words within their counting range and that a majority of children starts to master all number words between the age of 4 and 6 years. In Study 2, half of the children were still Small-numbers SS-knowers at 3 years 6 months. Even at 4 years 4 months, only $59 \%$ of the children mastered the cardinal meanings of all number words while $76 \%$ of them would have been considered by Wynn as CP-knowers (as only number words up to 6 were tested). Altogether, these results suggest that cardinal knowledge development continued far beyond the age of $3 \frac{1}{2}$ years for a majority of children, a period of acquisition that could extend to 6 years or more for a substantial number of children.

In accordance with these results, a large body of studies carried out since using other tasks demonstrated that the understanding of number words cardinal meanings is fragile and probably still incomplete in CP-knowers (identified 
using the GaN task). Indeed, as a group, CP-knowers performed above chance level in the Direction and the Unit tasks designed to assess the successor function, (i.e., understanding that adding vs. subtracting [one or two] item(s) to a set mean going forward vs. backward [of one or two steps] in the counting sequence; Sarnecka \& Carey, 2008). However, many CP-knowers did not completely figure out how counting represent numbers as they performed at chance level in these more demanding tasks (Davidson, Eng, \& Barner, 2012; Sarnecka \& Carey, 2008). Furthermore, only some $\mathrm{CP}$-knowers were able to produce larger number words to estimate larger numerosities (indicating that they master the later-greater principle) or to compare verbal number words in their counting list (Davidson et al., 2012; Le Corre, 2014; Odic et al., 2015; Sella \& Lucangeli, 2020), suggesting that they did not grasp the order-quantity analogy nested in the counting sequence. Thus, as claimed by Davidson, Eng, and Barner (2012), becoming a CP-knower in the GaN-task do not automatically involve a semantic induction for all numbers in the counting range and raises the possibility that children may be prompted, presumably by the instructions, to apply a blind procedure consisting of using counting to build the set to be given.

Altogether, these findings outlined how the acquisition of the cardinal meaning of number words is a multifaceted development. As such, it needs to be assessed using different tasks to have a complete picture of a child's cardinal knowledge. Instead of listing the cardinality related-concepts that are not fully mastered by CP-knowers (i.e., the successor function, later-greater principle, comparing number words), it is may be the concept of CP-knower it-self that should be reframed in a more integrated developmental framework considering the different conceptual dimensions of cardinal knowledge development that must be taken into account to be considered as a real CP-knower.

The time span of acquisition was the third issue addressed in this paper. In Wynn's (1992) study, 3-year-old children were tested every 5 to 8 weeks for 7 months and the author estimated that one-knowers or two-knowers spend at least 10 months on average before becoming three-knowers and/or finally CP-knowers. Based on longitudinal data, the time span of acquisition to achieve maximum cardinal knowledge in the present task was estimated at more than 9 months for Small-numbers SS-knowers (at least in the limit of the number words considered in the present studies). The knowledge of numbers up to one was reached around 3 years, up to three around $3 \frac{1}{2}$ years and of larger numbers around the age of 4 years. The longitudinal follow-up allowed estimating the time necessary to move from one cardinal knowledge level to the next one at nearly 6 months.

Finally, the last observation that came out from the present data sets was the huge variability in the developmental sequence from child to child, an observation consistent with Wynn (1992), Le Corre and Carey (2007) or Sarnecka and Lee (2009). In Study 1, very important differences were observed between the ages of children within the same cardinal knowledge level. Likewise, in Study 2, the time span of individual stages varied considerably from child to child. The most striking example was for Small-numbers SS-knowers whose age range spread out over 16 months (between 36 and 52 months). Nevertheless, the age range became narrower when cardinal knowledge level increased.

Although very similar, small differences exist with the original methodology used by Wynn (1992). A critical variation relates to the range of requested large number words which was determinant to revealed the existence of large SS-knowers (see also Krajcsi et al., 2018; Mussolin et al., 2012; Wagner \& Johnson, 2011). A second divergence bear on Wynn's success criteria which allowed the child to give the correct number according to his/her own stable counting sequence, even if it is incorrect. By contrast, in the present study, the child's own counting sequence was not taken in consideration. Just as in Le Corre and Carey (2007)' experiment, an answer was credited as correct only if the given number of objects was correct with one counting error accepted (then the correct number \pm 1 was credited). This difference makes our success criteria somewhat stricter than those used by Wynn. Crucially, in order not to induce a counting strategy and to prevent undue influence on the child's performance, the instruction never prompted the child to check his/her answer or recount, as was done in other studies (e.g., Le Corre et al., 2006; Sarnecka \& Lee, 2009; Wynn, 1992). As demonstrated by Krajcsi (2021), explicit recounting request has a massive influence on performance compared to the No follow-up question and the Is it N? versions of the task, leaving open two possible opposite interpretations. On one side, the recounting request avoids performance errors and prevents from underestimating the child cardinal knowledge. Under this assumption, the present result would underestimate the number of CP-knowers. On the other, the recounting instruction biases the performance, induces a strategy, which might translate into an overestimation of the child's cardinal knowledge. Further studies should focus on the concurrent validity of the different tasks/versions assessing cardinal knowledge to disentangle these two possible explanations. As an alternative, the Is it $n$ ? question 
provides an option in between. As far as can be seen from the results of Krajcsi (2021), it yields a similar pattern of performance as the no follow up instructions but it gives the child an opportunity to correct his/her answer.

Besides methodological considerations, the divergences in the pattern of acquisition of number words between the present sample of Belgian French-speaking preschoolers and American English-speaking children-many times replicated-might be related to subtle linguistic differences (Sarnecka et al., 2007). French and English shares many similarities in the grammatical use of numbers as both language present frequent singular/plural marking and make an anaphoric use of the word one in reference to the indefinite determiner $a(n)$ (e.g., I saw one on the table). However, French makes use of the same words for the number one (i.e., un in French) and the indefinite determiner $a(n)$ as a gender marker for masculine nouns. In English, the indefinite article $a(n)$ bears no mark of gender and is replaced by the word one only to suggest that there is more of the same thing (e.g., This is one example). Further cross-linguistic studies are necessary to determine how these subtle differences between French and English could influence the acquisition of number words.

The divergences could also be rooted in cultural factors. It is noteworthy that the few studies that reported large SS-knowers were mainly conducted in European countries (Belgian children in Mussolin et al., 2012; Hungarian preschoolers in Krajcsi et al., 2018; but see Wagner \& Johnson, 2011 for large SS-knowers in USA). Performance in the GaN task was found to be influenced by the cultures (Piantadosi et al., 2014; Sarnecka et al., 2007) and the socioeconomic status (Sarnecka et al., 2018; Scheuer et al., 2019). Future researches should provide more in-depth examination of the cultural factors hidden behind the socioeconomic status or the geographical localisation. Home numeracy activities (related to parents educational level) or teaching method (related to educational programs) have potentially greater explanatory power to unravel the cultural sources of variability in acquisition of numbers words (Piantadosi et al., 2014). In this respect, the number of numerical activities at home was found to be related to kindergartners' performance in mapping Arabic digits to non symbolic numerical representation (Marinova, Reynvoet, \& Sasanguie, 2021; Mutaf Yıldız, Sasanguie, De Smedt, \& Reynvoet, 2018).

In conclusion, the present study showed that acquiring the cardinal meanings of number words spread out over a protracted period, far more extended than assumed by Wynn, which could extend until the age of 6 years or more for a substantial number of children. Furthermore, children do not generalize all-at-once to large number words, the cardinal knowledge they have learned on small number words. Rather, number words were found to be learned one at a time in a more progressive manner. Although a great deal of work has been carried out on the fascinating issue of the symbol grounding problem, a lot remains to be done. Critically, future works should continue putting together the pieces that will lead to a thorough and integrative vision of the different facets of the development of number words cardinal meanings, beyond the GaN task. Understanding the conceptual source of the acquisition of number words cardinal meanings in a broader and more comprehensive way will allow to offer children new educational perspectives and reduce the huge variability observed in preschoolers.

Funding: This work was supported by the National Fund for Scientific Research of Belgium (FRS-FNRS; FRESH grant number: 1.F021.18).

Acknowledgments: We thank Maëlle Neveu, Sara Lebon and Ambre Morisse for their contribution to data collection. Finally, we are grateful to the headmasters, teachers, parents and children who accepted to participate in this project.

Competing Interests: The authors have declared that no competing interests exist.

Data Availability: For this article, a dataset is freely available (Rousselle \& Vossius, 2021).

\section{Supplementary Materials}

The dataset includes three sheets with data of Study 1 and 2. Regarding Study 1, the first sheet present participants' age (in years or months), their school grade and their performance in the numerical tasks (verbal number sequence, how-many and GaN tasks). The second sheet contains the data relative to the strategies used in the GaN task in Study 1. These data were used to analyse of the success profile, the answers, the frequency of grabbing / counting and the success / failure for each requested number). The last sheet reports the data collected for Study 2. The database includes participants' performance in GaN task according to age, the age at which 
each number word was acquired as well as the time spent by each participant to reach the next knowledge level with respect to their initial level of cardinal knowledge (for access see Index of Supplementary Materials below).

\section{Index of Supplementary Materials}

Rousselle, L., \& Vossius, L. (2021). Supplementary materials to "Acquiring the cardinal knowledge of number words: A conceptual replication" [Research data]. PsychOpen GOLD. https://doi.org/10.23668/psycharchives.5166

\section{References}

Almoammer, A., Sullivan, J., Donlan, C., Marušič, F., Žaucer, R., O’Donnell, T., \& Barner, D. (2013). Grammatical morphology as a source of early number word meanings. Proceedings of the National Academy of Sciences of the United States of America, 110(46), 18448-18453. https://doi.org/10.1073/pnas.1313652110

Carey, S. (2004). Bootstrapping \& the origin of concepts. Daedalus, 133(1), 59-68. https://doi.org/10.1162/001152604772746701

Carey, S. (2009). The origin of concepts. Oxford, United Kingdom: Oxford University Press.

Carey, S., Shusterman, A., Haward, P., \& Distefano, R. (2017). Do analog number representations underlie the meanings of young children's verbal numerals? Cognition, 168, 243-255. https://doi.org/10.1016/j.cognition.2017.06.022

Cheung, P., Slusser, E., \& Shusterman, A. (2016). A 6-month longitudinal study on numerical estimation in preschoolers. In A. Papafragou, D. Grodner, D. Mirman, \& J. C. Trueswell (Eds.), Proceedings of the 38th Annual Conference of the Cognitive Science Society (pp. 2813-2818). Austin, TX, USA: Cognitive Science Society.

Cohen, J. (1988). Statistical power analysis for the behavioral sciences. Hillsdale, NJ, USA: Lawrence Erlbaum Associates.

Davidson, K., Eng, K., \& Barner, D. (2012). Does learning to count involve a semantic induction? Cognition, 123(1), 162-173. https://doi.org/10.1016/j.cognition.2011.12.013

Dehaene, S. (1997). The number sense: How the mind creates mathematics. New York, NY, USA: Oxford University Press.

Dehaene, S., \& Changeux, J. P. (1993). Development of elementary numerical abilities: A neuronal model. fournal of Cognitive Neuroscience, 5(4), 390-407. https://doi.org/10.1162/jocn.1993.5.4.390

Feigenson, L., Dehaene, S., \& Spelke, E. (2004). Core systems of number. Trends in Cognitive Sciences, 8(7), 307-314. https://doi.org/10.1016/j.tics.2004.05.002

Frye, D., Braisby, N., Lowe, J., Maroudas, C., \& Nicholls, J. (1989). Young children's understanding of counting and cardinality. Child Development, 60(5), 1158-1171. https://doi.org/10.2307/1130790

Fuson, K. C., Richards, J., \& Briars, D. J. (1982). The acquisition and elaboration of the number word sequence. In C. J. Brainerd (Ed.), Children's logical and mathematical cognition: Progress in development research (pp. 33-92). New York, NY, USA: Springer.

Gallistel, C. R., \& Gelman, R. (1992). Preverbal and verbal counting and computation. Cognition, 44(1-2), 43-74. https://doi.org/10.1016/0010-0277(92)90050-R

Geary, D., Vanmarle, K., Chu, F., Hoard, M., \& Nugent, L. (2019). Predicting age of becoming a cardinal principle knower. fournal of Educational Psychology, 111(2), 256-267. https://doi.org/10.1037/edu0000277

Gelman, R., \& Gallistel, C. (1978). Young children's understanding of numbers. Cambridge, MA, USA: Harvard University Press.

Gunderson, E. A., Spaepen, E., \& Levine, S. C. (2015). Approximate number word knowledge before the cardinal principle. fournal of Experimental Child Psychology, 130, 35-55. https://doi.org/10.1016/j.jecp.2014.09.008

Huttenlocher, J., Jordan, N. C., \& Levine, S. C. (1994). A mental model for early arithmetic. fournal of Experimental Psychology: General, 123(3), 284-296. https://doi.org/10.1037/0096-3445.123.3.284

Krajcsi, A. (2021). Follow-up questions influence the measured number knowledge in the Give-a-number task. Cognitive Development, 57, Article 100968. https://doi.org/10.1016/j.cogdev.2020.100968

Krajcsi, A., Fintor, E., \& Hodossy, L. (2018). A refined description of preschoolers' initial symbolic number learning. OSF Preprints. https://doi.org/10.31219/osf.io/2kh9s

Le Corre, M. (2014). Children acquire the later-greater principle after the cardinal principle. British fournal of Developmental Psychology, 32(2), 163-177. https://doi.org/10.1111/bjdp.12029

Le Corre, M., \& Carey, S. (2007). One, two, three, four, nothing more: An investigation of the conceptual sources of the verbal counting principles. Cognition, 105(2), 395-438. https://doi.org/10.1016/j.cognition.2006.10.005 
Le Corre, M., Van de Walle, G., Brannon, E. M., \& Carey, S. (2006). Re-visiting the competence/performance debate in the acquisition of the counting principles. Cognitive Psychology, 52(2), 130-169. https://doi.org/10.1016/j.cogpsych.2005.07.002

Lee, M. D., \& Sarnecka, B. W. (2011). Number-knower levels in young children: Insights from Bayesian modeling. Cognition, 120(3), 391-402. https://doi.org/10.1016/j.cognition.2010.10.003

Marinova, M., Reynvoet, B., \& Sasanguie, D. (2021). Mapping between number notations in kindergarten and the role of home numeracy. Cognitive Development, 57, Article 101002. https://doi.org/10.1016/j.cogdev.2020.101002

Mix, K. S., Huttenlocher, J., \& Levine, S. C. (2002). Multiple cues for quantification in infancy: Is number one of them? Psychological Bulletin, 128(2), 278-294. https://doi.org/10.1037/0033-2909.128.2.278

Mussolin, C., Nys, J., Leybaert, J., \& Content, A. (2012). Relationships between approximate number system acuity and early symbolic number abilities. Trends in Neuroscience and Education, 1(1), 21-31. https://doi.org/10.1016/j.tine.2012.09.003

Mutaf Yıldız, B., Sasanguie, D., De Smedt, B., \& Reynvoet, B. (2018). Frequency of home numeracy activities is differentially related to basic number processing and calculation skills in kindergartners. Frontiers in Psychology, 9, Article 340. https://doi.org/10.3389/fpsyg.2018.00340

Negen, J., \& Sarnecka, B. W. (2012). Number-concept acquisition and general vocabulary development. Child Development, 83(6), 2019-2027. https://doi.org/10.1111/j.1467-8624.2012.01815.x

Negen, J., \& Sarnecka, B. W. (2015). Is there really a link between exact-number knowledge and approximate number system acuity in young children? British fournal of Developmental Psychology, 33(1), 92-105. https://doi.org/10.1111/bjdp.12071

Odic, D., Le Corre, M., \& Halberda, J. (2015). Children's mappings between number words and the approximate number system. Cognition, 138, 102-121. https://doi.org/10.1016/j.cognition.2015.01.008

Piantadosi, S. T., Jara-Ettinger, J., \& Gibson, E. (2014). Children's learning of number words in an indigenous farming-foraging group. Developmental Science, 17(4), 553-563. https://doi.org/10.1111/desc.12078

Piazza, M. (2011). Neurocognitive start-up tools for symbolic number representations. In S. Dehaene \& E. Brannon (Eds.), Space, time and number in the brain: Searching for the foundations of mathematical thought (pp. 267-285). Amsterdam, The Netherlands: Elsevier Academic Press. https://doi.org/10.1016/B978-0-12-385948-8.00017-7https://doi.org/10.1016/B978-0-12-385948-8.00017-7

Piazza, M., Mechelli, A., Butterworth, B., \& Price, C. J. (2002). Are subitizing and counting implemented as separate or functionally overlapping processes? NeuroImage, 15(2), 435-446. https://doi.org/10.1006/nimg.2001.0980

Posid, T., \& Cordes, S. (2018). How high can you count? Probing the limits of children's counting. Developmental Psychology, 54(5), 875-889. https://doi.org/10.1037/dev0000469

Revkin, S. K., Piazza, M., Izard, V., Cohen, L., \& Dehaene, S. (2008). Does subitising reflect numerical estimation? Psychological Science, 19(6), 607-614. https://doi.org/10.1111/j.1467-9280.2008.02130.x

Reynvoet, B., \& Sasanguie, D. (2016). The symbol grounding problem revisited: A thorough evaluation of the ANS mapping account and the proposal of an alternative account based on symbol-symbol associations. Frontiers in Psychology, 7, Article 1581. https://doi.org/10.3389/fpsyg.2016.01581

Sarnecka, B. W. (2021). Learning to represent exact numbers. Synthese, 198, 1001-1018. https://doi.org/10.1007/s11229-015-0854-6

Sarnecka, B. W., \& Carey, S. (2008). How counting represents number: What children must learn and when they learn it. Cognition, 108(3), 662-674. https://doi.org/10.1016/j.cognition.2008.05.007

Sarnecka, B. W., \& Gelman, S. A. (2004). Six does not just mean a lot: Preschoolers see number words as specific. Cognition, 92(3), 329-352. https://doi.org/10.1016/j.cognition.2003.10.001

Sarnecka, B. W., Goldman, M. C., \& Slusser, E. B. (2015). How counting leads to children's first representations of exact, large numbers. In R. C. Kadosh \& A. Dowker (Eds.), The Oxford handbook of numerical cognition (pp. 291-309). Oxford, United Kingdom: Oxford University Press. https://doi.org/10.1093/oxfordhb/9780199642342.013.011

Sarnecka, B. W., Kamenskaya, V. G., Yamana, Y., Ogura, T., \& Yudovina, Y. B. (2007). From grammatical number to exact numbers: Early meanings of "one", "two", and "three" in English, Russian, and Japanese. Cognitive Psychology, 55(2), 136-168. https://doi.org/10.1016/j.cogpsych.2006.09.001

Sarnecka, B. W., \& Lee, M. D. (2009). Levels of number knowledge during early childhood. fournal of Experimental Child Psychology, 103(3), 325-337. https://doi.org/10.1016/j.jecp.2009.02.007

Sarnecka, B. W., Negen, J., \& Goldman, M. C. (2018). Early number knowledge in dual-language learners from low-SES households. In D. B. Berch, D. C. Geary, \& K. M. Koepke (Eds.), Language and culture in mathematical cognition (pp. 197-228). Amsterdam, The Netherlands: Elsevier Academic Press. https://doi.org/10.1016/B978-0-12-812574-8.00009-2 
Scheuer, N., Martí, E., Cavalcante, S., \& Brizuela, B. M. (2019). Response patterns of young children from two contrasting SES contexts to different numerical tasks with numbers 1-5. The fournal of Genetic Psychology, 180(1), 1-16.

https://doi.org/10.1080/00221325.2018.1562417

Schneider, R. M., Pankonin, A., Schachner, A., \& Barner, D. (2021). Starting small: Exploring the origins of successor function knowledge. Developmental Science, 24, Article e13091. https://doi.org/10.1111/desc.13091

Secada, W. G., Fuson, K. C., \& Hall, J. W. (1983). The transition from counting-all to counting-on in addition. fournal for Research in Mathematics Education, 14(1), 47-57. https://doi.org/10.2307/748796

Sella, F., Lanfranchi, S., \& Zorzi, M. (2013). Enumeration skills in Down syndrome. Research in Developmental Disabilities, 34(11), 3798-3806. https://doi.org/10.1016/j.ridd.2013.07.038

Sella, F., \& Lucangeli, D. (2020). The knowledge of the preceding number reveals a mature understanding of the number sequence. Cognition, 194, Article 104104. https://doi.org/10.1016/j.cognition.2019.104104

Sella, F., Lucangeli, D., Cohen Kadosh, R., \& Zorzi, M. (2020). Making sense of number words and Arabic digits: Does order count more? Child Development, 91(5), 1456-1470. https://doi.org/10.1111/cdev.13335

Shusterman, A., Slusser, E., Halberda, J., \& Odic, D. (2016). Acquisition of the cardinal principle coincides with improvement in approximate number system acuity in preschoolers. PLoS One, 11(4), Article e0153072. https://doi.org/10.1371/journal.pone.0153072

Simon, T. J. (1997). Reconceptualizing the origins of number knowledge: A "non-numerical” account. Cognitive Development, 12(3), 349-372. https://doi.org/10.1016/S0885-2014(97)90008-3

Slusser, E., Ditta, A., \& Sarnecka, B. (2013). Connecting numbers to discrete quantification: A step in the child's construction of integer concepts. Cognition, 129(1), 31-41. https://doi.org/10.1016/j.cognition.2013.05.011

Slusser, E. B., \& Sarnecka, B. W. (2011). Find the picture of eight turtles: A link between children's counting and their knowledge of number word semantics. Fournal of Experimental Child Psychology, 110(1), 38-51. https://doi.org/10.1016/j.jecp.2011.03.006

Spelke, E. S., \& Kinzler, K. S. (2007). Core knowledge. Developmental Science, 10(1), 89-96. https://doi.org/10.1111/j.1467-7687.2007.00569.x

Stoianov, I., \& Zorzi, M. (2012). Emergence of a "visual number sense" in hierarchical generative models. Nature Neuroscience, 15(2), 194-196. https://doi.org/10.1038/nn.2996

Trick, L. M., \& Pylyshyn, Z. W. (1994). Why are small and large numbers enumerated differently? A limited-capacity preattentive stage in vision. Psychological Review, 101(1), 80-102. https://doi.org/10.1037/0033-295X.101.1.80

Wagner, J. B., \& Johnson, S. C. (2011). An association between understanding cardinality and analog magnitude representations in preschoolers. Cognition, 119(1), 10-22. https://doi.org/10.1016/j.cognition.2010.11.014

Wagner, K., Chu, J., \& Barner, D. (2019). Do children's number words begin noisy? Developmental Science, $22(1)$, Article e12752. https://doi.org/10.1111/desc. 12752

Whalen, J., Gallistel, C. R., \& Gelman, R. (1999). Nonverbal counting in humans: The psychophysics of number representation. Psychological Science, 10(2), 130-137. https://doi.org/10.1111/1467-9280.00120

Wynn, K. (1990). Children's understanding of counting. Cognition, 36(2), 155-193. https://doi.org/10.1016/0010-0277(90)90003-3

Wynn, K. (1992). Children's acquisition of the number words and the counting system. Cognitive Psychology, 24(2), $220-251$. https://doi.org/10.1016/0010-0285(92)90008-P 


\section{Appendix}

\section{Table A1}

Distribution of Children in Each Cardinal Knowledge Group According to the Age

\begin{tabular}{|c|c|c|c|c|c|c|c|c|c|}
\hline \multirow[b]{2}{*}{ Age } & \multicolumn{9}{|c|}{ Cardinal Knowledge Level } \\
\hline & $\mathbf{0}$ & 1 & 2 & 3 & 4 & 5 & 6 & 7 & Total \\
\hline 3 years & $\mathbf{0}$ & $\mathbf{0}$ & 11 & 3 & 3 & 1 & $\mathbf{0}$ & 7 & 25 \\
\hline $3 ; 0-3 ; 3$ & 0 & 0 & 1 & 1 & 1 & 1 & 0 & 1 & 5 \\
\hline $3 ; 4-3 ; 7$ & 0 & 0 & 6 & 1 & 1 & 0 & 0 & 1 & 9 \\
\hline $3 ; 8-3 ; 11$ & 0 & 0 & 4 & 1 & 1 & 0 & 0 & 5 & 11 \\
\hline 4 years & 1 & 4 & 21 & 19 & 18 & 5 & 7 & 44 & 119 \\
\hline $4 ; 0-4 ; 3$ & 1 & 1 & 6 & 6 & 7 & 1 & 4 & 11 & 37 \\
\hline $4 ; 4-4 ; 7$ & 0 & 1 & 8 & 6 & 8 & 2 & 2 & 10 & 37 \\
\hline $4 ; 8-4 ; 11$ & 0 & 2 & 7 & 7 & 3 & 2 & 1 & 23 & 45 \\
\hline 5 years & 1 & 1 & $\mathbf{0}$ & 1 & 4 & 6 & 8 & 42 & 63 \\
\hline $5 ; 0-5 ; 3$ & 1 & 0 & 0 & 1 & 3 & 2 & 3 & 13 & 23 \\
\hline $5 ; 4-5 ; 7$ & 0 & 1 & 0 & 0 & 0 & 2 & 3 & 11 & 17 \\
\hline $5 ; 8-5 ; 11$ & 0 & 0 & 0 & 0 & 1 & 2 & 2 & 18 & 23 \\
\hline 6 years & $\mathbf{0}$ & $\mathbf{0}$ & $\mathbf{0}$ & $\mathbf{0}$ & $\mathbf{0}$ & $\mathbf{0}$ & $\mathbf{0}$ & 6 & 6 \\
\hline $6 ; 0-6 ; 3$ & 0 & 0 & 0 & 0 & 0 & 0 & 0 & 6 & 6 \\
\hline $6 ; 4-6 ; 7$ & 0 & 0 & 0 & 0 & 0 & 0 & 0 & 0 & 0 \\
\hline \multirow[t]{2}{*}{$6 ; 8-6 ; 11$} & 0 & 0 & 0 & 0 & 0 & 0 & 0 & 0 & 0 \\
\hline & 2 & 5 & 32 & 23 & 25 & 12 & 15 & 99 & 213 \\
\hline
\end{tabular}

Note. Age is reported in years; months.

\section{Table A2}

The Detailed Evolution of Children Through Knower-Levels According to Their Initial Level of Cardinal Knowledge

\begin{tabular}{|c|c|c|c|c|}
\hline Initial Level $(n=34)$ & +4 Months & +8 Months & +12 Months & +16 Months \\
\hline \multicolumn{5}{|c|}{ Pre-numeral-knowers $(n=4)$} \\
\hline Pre- & 0 & 0 & 0 & 0 \\
\hline Small & 4 & 3 & 2 & 1 \\
\hline Large & 0 & 1 & 2 & 0 \\
\hline Max & 0 & 0 & 0 & 3 \\
\hline \multicolumn{5}{|l|}{$0-k(n=4)$} \\
\hline $0-\mathrm{k}$ & 0 & 0 & 0 & 0 \\
\hline $1-\mathrm{k}$ & 0 & 0 & 0 & 0 \\
\hline $2-\mathrm{k}$ & 4 & 2 & 1 & 1 \\
\hline $3-\mathrm{k}$ & 0 & 1 & 1 & 0 \\
\hline $4-\mathrm{k}$ & 0 & 0 & 1 & 0 \\
\hline $5-\mathrm{k}$ & 0 & 1 & 1 & 0 \\
\hline $6-\mathrm{k}$ & 0 & 0 & 0 & 0 \\
\hline $7-\mathrm{k}$ & 0 & 0 & 0 & 3 \\
\hline
\end{tabular}




\begin{tabular}{|c|c|c|c|c|}
\hline Initial Level $(n=34)$ & +4 Months & +8 Months & +12 Months & +16 Months \\
\hline \multicolumn{5}{|c|}{ Small numbers SS-knowers $(n=29)$} \\
\hline Small & 26 & 16 & 9 & 4 \\
\hline Large & 3 & 12 & 20 & 9 \\
\hline $\operatorname{Max}$ & 0 & 0 & 0 & 16 \\
\hline \multicolumn{5}{|l|}{$1-k(n=6)$} \\
\hline $1-\mathrm{k}$ & 3 & 2 & 0 & 2 \\
\hline $2-\mathrm{k}$ & 2 & 2 & 3 & 0 \\
\hline $3-\mathrm{k}$ & 1 & 1 & 1 & 0 \\
\hline $4-\mathrm{k}$ & 0 & 0 & 0 & 0 \\
\hline $5-\mathrm{k}$ & 0 & 1 & 2 & 0 \\
\hline $6-\mathrm{k}$ & 0 & 0 & 0 & 0 \\
\hline $7-\mathrm{k}$ & 0 & 0 & 0 & 4 \\
\hline \multicolumn{5}{|l|}{$2-k(n=17)$} \\
\hline $2-\mathrm{k}$ & 12 & 5 & 2 & 0 \\
\hline $3-\mathrm{k}$ & 4 & 5 & 2 & 1 \\
\hline $4-\mathrm{k}$ & 1 & 3 & 6 & 2 \\
\hline $5-\mathrm{k}$ & 0 & 3 & 7 & 2 \\
\hline $6-\mathrm{k}$ & 0 & 0 & 0 & 3 \\
\hline $7-\mathrm{k}$ & 0 & 0 & 0 & 9 \\
\hline \multicolumn{5}{|l|}{$3-k(n=6)$} \\
\hline $3-\mathrm{k}$ & 4 & 1 & 1 & 1 \\
\hline $4-\mathrm{k}$ & 1 & 1 & 1 & 1 \\
\hline $5-\mathrm{k}$ & 1 & 4 & 4 & 1 \\
\hline $6-\mathrm{k}$ & 0 & 0 & 0 & 0 \\
\hline $7-\mathrm{k}$ & 0 & 0 & 0 & 3 \\
\hline \multicolumn{5}{|c|}{ Large numbers SS-knowers $(n=1)$} \\
\hline Large & 1 & 1 & 1 & 0 \\
\hline Max & 0 & 0 & 0 & 1 \\
\hline \multicolumn{5}{|l|}{$5-k(n=1)$} \\
\hline $5-\mathrm{k}$ & 1 & 1 & 1 & 0 \\
\hline $6-\mathrm{k}$ & 0 & 0 & 0 & 0 \\
\hline 7-k & 0 & 0 & 0 & 1 \\
\hline
\end{tabular}

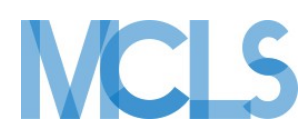

Journal of Numerical Cognition (JNC) is an official journal of the Mathematical Cognition and Learning Society (MCLS).

\section{(P) leibniz-psychology.org}

PsychOpen GOLD is a publishing service by Leibniz Institute for Psychology (ZPID), Germany. 